\title{
Investigation of Flow and Heat Transfer Characteristics in Two-Phase Flow Through Evaporator of Diffusion Absorption Refrigerator (DAR)
}

\author{
Siti Masita Rakhmawati
}

\begin{abstract}
The application of the cooling system becomes very important for a comfortable and almost all public buildings in Indonesia using the cooling system. The cooling system is commonly requires considerable electrical power to drive the compressor used for the vapor compression cooling system in operation. Different with the diffusion absorption refrigeration system, all cycles in the system are occurred by natural circulation where the refrigerant is pressurized (partial) lower in the evaporator is obtained with the aid of an inert gas that can be either hydrogen or helium, which is mixed with the refrigerant gas, but not also react. The study was conducted by flowing the refrigerant at the evaporator copper tube passes that are part of a diffusion absorption refrigeration machine. Long dimension of passes evaporator is $2.38875 \mathrm{~m}$. The method used in this study is the experimental and numerical approach, which is using Multiphase Flow Fluent CFD 6.3. simulation to validate the experimental observations of flow.Through this study, the fenonena happened to be validated by experimental observations numerically. Also can be seen flow characteristics of refrigerant flowing along the evaporator and heat transfer phenomena that occur.
\end{abstract}

Keywords—cooling system, refrigerant, flow, multiphase, natural circulation, experiment, simulation, fluent.

\section{INTRODUCTION}

$\mathrm{T}$ ube/channel evaporators are widely employed in various energy systems, like HVACR and petrochemical industries. As well-known, both associated flow boiling and two phase flow play very important roles in evaporators and are still far from being fully understood. As a result, present evaporators are normally designed with a profuse safety factor, resulting in an unnecessary tube length and high superheat of vapor at the exit. Further understanding of flow boiling could potentially decrease the manufacture cost and energy consumption, and furthermore obtain better performance.

Flow boiling and associated two phase flow in tubes/ channels was comprehensively investigated as a classical topic of boiling heat transfer in open literature. Particularly, numerous investigations were conducted for horizontal, adiabatic gas-liquid two-phase flow in tubes. Two-phase flow with phase change is very complicated. In addition to inertia, viscous and pressure forces present in single-phase flow, two-phase flows are greatly affected by interfacial tension forces, the wetting characteristics of the liquid on the tube wall and the exchange of momentum between the liquid and vapor phases in the flow, also by phase distribution, mass exchange among two phases, flow pattern evolution and phase redistribution if with phase change. Usually, traditional liquid-gas flow modes in a horizontal tube includes bubbly flow, plug flow, slug flow, wavy flow and annular flow, and also stratified flow, stratified/wavy flow, intermittent flow, mist flow and so on.

\footnotetext{
${ }^{1}$ Siti Masita Rakhmawati is with Departement of Mechanical Engineering, Faculty of Industrial Engineering, Institut Teknologi Sepuluh Nopember, Surabaya, 60111, Indonesia. E-mail: sitimasitarakhmawati@gmail.com.
}

Today the use of the cooling system becomes very important for a comfort almost all offices, hotels, laboratories and public buildings in Indonesia using the cooling system. Besides being used to support human activities in space, the cooling system is also used in industrial fields such as food preservation, petroleum, and petrochemical. The cooling system is commonly used for this is where the vapor compression cooling system in operation requires considerable electrical power to drive the compressor.

As with vapor compression cooling systems, absorption refrigeration operation with the condenser, expansion valve and evaporator. But the difference with vapor compression system that uses a compressor to raise the pressure of the refrigerant, the vapor absorption system component is replaced by a generator, absorber, pump and expansion valve. On generators given amount of heat that the refrigerant (in solution) evaporates and the pressure increased, while the absorber occurs heat release results from absorption reaction (exothermic) which the absorbent (weak solution) absorbs the refrigerant. This is very advantageous because the heat energy required to run the process in the generator can be obtained easily, either from a high level of energy obtained directly from the combustion process or from combustion heat energy being emitted into the stack, abundant solar energy, geothermal energy and other heats.

Development of one absorption cooling system cooling system with different diffusion absropsi arbsorpsi conventional systems. In the conventional absorption systems with a cooling capacity large enough to evaporatornya refrigerant pressure drop is obtained by passing the refrigerant condensate from the condenser to an expansion valve so that the refrigerant temperature also decreased. While the diffusion absorption cooling system, all cycles occurring in the system where the refrigerant is pressurized natural circulation (partial) lower in the evaporator is obtained with the aid of an 
inert gas that can be either hydrogen or helium, which is mixed with the refrigerant gas but also react. This gas acts to control the total pressure of the fluid in the evaporator is equal to the total pressure on other components, as well as the partial pressure of the liquid refrigerant remains low.

In everyday life than one phase flow, multiphase flow is also found in a variety of applications. For example, in the piping system, the boiler, the nuclear power plants, the oil industry and others. Multiphase flow itself can be divided into several sections, there are two phase flow, three-phase, or more.

Two-phase flow is still able to be divided into several parts again, seen from the accompanying phase, the flow of liquid-solid two-phase, liquid-gas, and gas-solid. Aside from the two-phase flow phase is also distinguished by the direction of flow (direction and the opposite direction) and the position of the line (vertical, horizontal, or oblique).

Two-phase flow is often found both in everyday life and in industrial processes, such as boilers, condensers, heat exchangers, nuclear reactors, natural gas liquefaction, pipelines and others. Two-phase flow, which is part of a multiphase flow is very different from the single-phase flow. In the single-phase flow, pressure drop is influenced by the Reynolds number is a function of viscosity, fluid density and diameter of the pipe. While the two-phase flow has a very complex phenomenon than the flow of one phase of which is the interaction between the phases, the influence of surface deformation and movement between fluid, phase imbalance influences, changes in flow patterns and so forth. Not unless also pressure drop in two-phase flow became much interest in research.

Multiphase flow in closed channels (pipes) are not only affected by the Reynolds number, but the phases are mixed in it has a significant impact so that there will be a lot of flow regime (flow pattern) is formed in the channel due to the interaction between the fluid phase. Flow changes the flow pattern (flow regime) can cause pressure drop too fickle or fluctuating.

In the cooling unit in the DAR all cycles occur naturally circulation system where the refrigerant pressure ( partial ) lower in the evaporator is obtained with the aid of an inert gas that can be either hydrogen or helium, which is mixed with the refrigerant gas but also react. This gas acts to control the total pressure of the fluid in the evaporator is equal to the total pressure on other components, as well as the partial pressure of the liquid refrigerant remains low .

Meanwhile in the evaporator of the refrigerant changes phase from liquid to gas saturation that occurs at temperatures and pressures that keep total . Mass flow rate in the pipeline also drove very low due to the natural circulation. Then for the corresponding simulation mempuat and actually required the election approached keaadan multiphase appropriate method for modeling the evaporator .

In 2007 , H.L. Wu et al conducted a study with numerical simulations to investigate the flow of refrigerant is boiling on a horizontal circular tube is modeled as the method of Eulerian multiphase flow and phase change model for the mass transfer. While $\mathrm{Z}$. Yang et al (2008) conducted a numerical simulation , using the VOF multiphase flow model and corresponding experiments carried out to investigate the flow boiling R141B in a horizontal circular tube . Numerical prediction evolutionary phases are in good agreement with experimental observations, and the twophase flow in the tube bend is much more complicated because of the influence of the interaction with the liquid-vapor interface evolution. Then I Nengah Ardita in 2008 did an experimental study of the diffusion absorption cycle using R22-DMF as a couple referigeran and absorbent, and hydrogen as the inert gas.

In the present paper, an attempt was made to combine the experimental observation with numerical simulation to explore and understand fundamentals of two-phase flow behavior during flow boiling in coiled tubes. Numerical simulations were conducted for flow boiling in a horizontal coiled tube using refrigerant R-22 as the work fluid. Special interests were addressed on the flow mode evolution and exploring the details of local flow and transport phenomena. Meanwhile, an experiment was conducted to validate the simulations.

\section{METHOD}

\section{A. Basic considerations}

The modeling of boiling flow was accomplished by using Laminar in CFD software Fluent 6.0 in Laminar model, volume fractions of each phase in a computational cell are recorded, and volume fractions of all phases sum to unity.

$\alpha_{l}+\alpha_{v}=1$

Information on phase distribution can be directly extracted from the volume fractions. For instance, the computational grid is empty or full of the liquid when $\alpha_{1}$ reaches the minimum value of zero or the maximum value of unit, and contains phase interface with $\alpha_{1}$ between 0 and 1 .

The tracking of the interface between phases was accomplished by solving continuity equations for the volume fractions of different phases. For the liquid and vapor phases, the equations are:

$\frac{\partial \alpha_{l}}{\partial t}+\nabla \cdot\left(\vec{v} \alpha_{l}\right)=\frac{s}{\rho_{l}}$
$\frac{\partial \alpha_{v}}{\partial t}+\nabla \cdot\left(\vec{v} \alpha_{v}\right)=\frac{s}{\rho_{v}}$

The continuity, momentum and energy equations are, respectively,

$$
\begin{aligned}
& \frac{\partial(\rho \vec{v})}{\partial t}+\nabla \cdot(\rho \vec{v} \vec{v}) \\
& =-\nabla p+\nabla \cdot\left[\mu\left(\nabla \vec{v}+\nabla \vec{v}^{T}\right)-\frac{2}{3} \mu \nabla \cdot \vec{v} l\right]+\rho \vec{g}+F_{v o l} \\
& \frac{\partial(\rho E)}{\partial t}+\nabla \cdot[\vec{v}(\rho E+p)]=\nabla \cdot(\mathrm{k} \nabla \mathrm{T})+\mathrm{Q}
\end{aligned}
$$

Where,

$$
\begin{aligned}
\rho & =\alpha_{l} \rho_{l}+\alpha_{v} \rho_{v} \\
k & =\alpha_{l} k_{l}+\alpha_{v} k_{v} \\
\mu & =\alpha_{l} \mu_{l}+\alpha_{v} \mu_{v} \\
E & =\frac{\alpha_{l} \rho_{l} E_{l}+\alpha_{v} \rho_{v} E_{v}}{\alpha_{l} \rho_{l}+\alpha_{v} \rho_{v}} \\
E_{l} & =C_{v, l}(T-298,15), E_{v}=C_{v, v}(T-298,15)
\end{aligned}
$$


The accuracy of the temperature near the interface is considerably corrupt in cases where large temperature differences exist between the phases. Such problems also arise in cases where the properties vary by several orders of magnitude. For example, if a model includes liquid metal in combination with air, the conductivities of the materials can have difference as much as four orders of magnitude. Such large discrepancies in properties lead to equation sets with anisotropic coefficients, which can consequently lead to the issues of convergence and precision.

In FLUENT, a formulation of the continuum surface force (CSF) model is used, and the surface tension can finally be written in terms of the pressure jump across the surface. The force at the surface can be expressed as a volume force $\mathrm{F}_{\mathrm{vol}}$, using the divergence theorem. The volume force acts as the source term in the momentum equation and has the following form:

$F_{v o l}=\sigma_{l v} \frac{\alpha_{l} \rho_{l} K_{v} \nabla \alpha_{v}+\alpha_{v} \rho_{v} K_{l} \nabla \alpha_{l}}{0.5\left(\rho_{l}+\rho_{v}\right)}$

where $\sigma_{\mathrm{lv}}$ is the interfacial tension between the liquid and vapor. The curvatures of liquid and vapor are defined as

$K_{l}=\frac{\Delta \alpha_{l}}{\left|\nabla \alpha_{l}\right|}, \quad K_{v}=\frac{\Delta \alpha_{v}}{\left|\nabla \alpha_{v}\right|}$

The geometric reconstruction scheme represents the interface between fluids using a piecewise-linear approach. In FLUENT this scheme is the most accurate and is applicable for general unstructured meshes. The pressure-implicit with splitting of operators (PISO) pressure-velocity coupling scheme, part of the SIMPLE family of algorithms, is based on the higher degree of the approximate relation between the corrections for pressure and velocity. Compared with the SIMPLE and SIMPLEC algorithms, the PISO algorithm performs two additional corrections: neighbor correction and skewness correction. These corrections help to improve the efficiency of calculation.

\section{B. Transport description}

1) Heat transfer

The heat transfer was simply determined from the mass rate of evaporation or condensation, in addition to the conduction and convection. As long as the mass transfer was obtained, the heat transfer could be directly determined as

$Q=-h_{l h} S$

2) Geometrical configuration

The geometry to be drawn on Gambit is part of the evaporator Sink DAR that has been modified, with dimensions as shown in Figure 2 and Figure 3. It has six of a straight pipe length are identical, while the semicircular pipe has a central circle radius (R) equal to five. So the length of the evaporator is $2,38875 \mathrm{~m}$

3) Working fluids

Cholodifluoromethane or difluoromonochlorometane is a hydrochlorofluorocarbon (HCFC). This colorless gas is beteer known as HCFC-22, or R-22. It is commonly used as a propellant and refrigerant. These applications are being phased out in developed countries due to the compound's ozone depletion potential (ODP) and high global warming potential (GWP), although global use of R-22 continues to increase because of high demand in developing countries. Dimethylformamide is an organic compound with the formula $\left(\mathrm{CH}_{3}\right)_{2} \mathrm{NC}(\mathrm{O}) \mathrm{H}$. Commonly abbreviated as DMF (although this acronym is sometimes used for dimethylfuran), this colourless liquid is miscible with water and the majority of organic liquids. DMF is a common solvent for chemical reactions.

\section{Flow patterns}

The complete development of flow mode in a straight heating tube mainly consists of six different regimes, namely bubbly, churn, slug, stratified, annular and mist flow. Under proper working conditions, e.g. flowrate, heat flux, inlet liquid temperature and pressure, these flow modes can be observed in both simulations and experiments conducted for a coiled tube.

1) Flow regimes in horizontal pipes

One of the most challenging aspects of dealing with multi-phase flow is the fact that it can take many different forms. In the case of gas-liquid flow, the gas may appear as tiny amounts of small bubbles in the liquid. That kind of flow occurs when there is relatively little gas compared to liquid, at the same time as the liquid flows fast enough to create sufficient turbulence to mix the gas into the liquid faster than the gas can rise to the top of the pipe.

Another extreme occurs if tiny amounts of liquid droplets are carried by the gas. In that case part of the liquid becomes deposited on the pipe's surface and moves as a film in much the same way water moves on the windscreen of a car driving in the rain. Remember that since pressures can be high in pipelines, the gas density is typically much higher that what we are used to experience for air, and even moderate gas velocities can have great impact. Annular droplet flow can be relatively difficult to model accurately since the model needs to incorporate such effects as how fast the droplets are torn from the liquid film, how fast droplets settle on the liquid film, and how the liquid film affects the surface roughness between gas and liquid. In many cases, however, the resulting accuracy is acceptable for our purpose, since this kind of flow does not create the same sorts of problems as slugging does. But it can lead to the various secondary calculations of deposition or corrosion, which use results from the flow models as their input, becoming less accurate.

Figure 4 illustrates the flow regimes we can encounter in horizontal two-phase gas- liquid flow. Stratified flow has the strongest tendency to occur in downhill or horizontal flow with relatively small gas and liquid flow rates. If we increase the gas velocity, waves start to form, and these waves can get high enough to reach the top of the pipe. When that happens, the gas is throttled or even blocked for a moment so that the flow becomes discontinuous, thus leading to the formation of slugs or elongated bubbles. Slugs are generally unwanted because they can create significant pressure fluctuations, and they can also lead to gas and liquid arriving at the processing facilities unevenly, causing tanks to flood. Since gases have lower density and therefore lower heat capacity than liquids, gases cool faster, 
so the temperature reduction during periods of high gas content can more easily cause hydrates to form. The increased intermittent liquid velocity can also accelerate corrosion.

2) Flow regimes in vertical pipes

The flow regimes occurring in vertical are similar to those in horizontal pipes, but one difference being that the there is no lower side of the pipe which the densest fluid 'prefers'. One of the implications this has is that stratified flow is not possible in vertical pipes.

\section{RESULT AND DISCUSSION}

The complete development of flow mode in a straight heating tube mainly consists of six different regimes, namely bubbly, churn, slug, stratified, annular and mist flow. Under proper working conditions, e.g. flowrate, heat flux, inlet liquid temperature and pressure, these flow modes can be observed in both simulations and experiments conducted for a coiled tube. In this investigation, six working conditions were investigated both numerically and experimentally.

Generally, the flow patterns numerically predicted are in a good agreement with the experimental observations. Bubbly flow appeared in In the entrance region of the coiled tube, the fluid is subcooled, and the applied heat amount mainly contributes to raise the fluid temperature. Either decreasing wall heat flux or increasing the mass flowrate would extend the bubbly flow region significantly.

Along the flow direction, small bubbles, absorbing vapor or coalescing with other bubbles, continuously grow up, and the flow gradually changes into a churn type. The a typical slug flow region appeared because the wall heat flux is small and a relatively long flow distance is needed for the fluid to absorb the amount of energy enough for the transition from slug flow into stratified flow. After the stratified mode, the flow turns into a wavy type. The fluid is further accelerated due to liquid vaporization, meanwhile the strong viscous shearing causes the vapor-liquid interface drastically waving. The computed waving thin liquid layer tends to break into liquid patches rather than maintain a continuous film on the tube surface. Further study shows that the coarse grid configuration is mainly responsible for the broken thin liquid film. When the film is thinner than the thickness of one grid, flow fluctuation is easy to break the film into separate liquid patches, as shown in Figure 6. Flow in straight tube, once a small vapor is formed at the active site, it flows upward and downstreamwise due to the effects of the buoyancy and flow flushing, forming a small bubble stream. These small bubbles, floating on the top of the tube, continuously grow up, and subsequently evolve into slugs. In the further downstream region, the slugs are easy to coalesce into continuous vapor region and the flow mode turns into a stratified one. The pressure appears the highest in the most upstream straight tube section and the lowest in the most downstream straight tube section. In a specified straight tube section, gravity governs the pressure distribution, the pressure generally decreasing along vertical direction. Due to the surface tension, higher pressure appears in the interior of small bubbles, as seen in the most upstream straight tube section. The highest velocity appears in the vapor layer of the most downstream straight tube section, as shown in Figure 7.

Boiling flow in tube bends is quite different from that in straight tubes due to the influence of centrifugal force coupled with the buoyancy. Liquid-vapor interface may be expected to play a dominant role in pressure and velocity distributions. The velocity vectors of secondary flow and pressure significantly differ from each other on different cross-sections since the acceleration of fluid induced by the volumetric expansion of evaporation changes with flow distance and significantly alters the fluid velocity. Also, the phase re-distribution induced by bend effects has great impact on the flow behavior in the bends. Figure 8 shows the distributions of secondary flow and pressure on bend cross-sections for R141B flowing without phase change. Numerical simulations and experiments were conducted to investigate the flow boiling of refrigerant R-22 in a horizontal coiled tube. The simulations comprehensively exhibited the evolution process of flow mode depending on hydrodynamical and thermal flow conditions. Flow velocity predicted in the simulations showed a strongly dependence on the phase distribution. In bubbly flow vapor phase flowed with liquid phase, showing less difference of velocities between two phases, whereas in stratified flow vapor flowed much faster than liquid did and caused the phase interface to wave significantly. Special interests were addressed on the flow in the tube bends, and the study on secondary flow in these tube bends showed that liquidvapor interface, in addition to the centrifugal force and buoyancy, played a dominant role in pressure and velocity profiles.

\section{REFERENCES}

[1]. Ambesa. Wilson, “Analisa Termodinamis Performansi Mesin Pendingi Sistem Difusi Absorpsi Amoniak-Air dengan Variasi Panas Generator", Tugas Akhir Teknik Mesin FTI-ITS Surabaya, 2010.

[2]. Ardita. Nengah, "Analisa Performansi Sistem Pendingi Difusi Absorpsi DMF-R22”, Thesis Teknik Mesin FTI-ITS Surabaya, 2007.

[3]. Frank P. Incropera dan David P. Dewitt, "Fundamentals of Heat and Mass Transfer Fifth Edition", New York :John Wiley and Sons, 1996, pp. 20-50

[4]. Mahara, Khrisma (2010) "Analisa Perpindahan Panas pada Evaporator Tipe Double Turbular Pipe pada Unit Pendingin Difusi Absorpsi Amoniak-Air dengan Variasi Beban Pendinginan dan Daya Generator ", Tugas Akhir Teknik Mesin FTI- ITS Surabaya

[5]. Moran M.J dan Shapiro H.N, "Fundamental of Engineering Thermodynamics, Fourth Edition", New York : John Willey and Sons, 1996.

[6]. Robert H.Perry dan Don W.Green, "Perry's Chemical Engineer's Handbook, Seventh Edition", USA: Mc Graw-Hill, 1999.

[7]. Wibert F.Stocker, Jerold W. Jones, Supratman Hara, "Refrigerasi dan Pengkondisian Udara, Edisi Kedua", Jakarta : Penerbit Erlangga, 1994.

[8]. Zohar, M. Jelinek, A. Levy, I. Borde, "The Influence of Diffusion Asorption Refrigeration Cycle Configuration on The Performance", Applied Thermal Engineering : Science Direct, 2005.

[9]. H.L. Wua, X.F. Peng, P. Yea, Y. Eric Gong, "Simulation of refrigerant flow boiling in serpentine tubes", International Journal of Heat and Mass Transfer 50 1186-1195 : Science Direct, 2007.

[10]. O. Laguere, D. Flick, "Heat Transfer by natural convection in domestic refrigerators", Journal of Food Engineering: Science Direct, 2003

[11]. Z. Yang, X.F. Peng, P. Ye, "Numerical and experimental investigation of two phase flow during boiling in a coiled tube", International Journal of Heat and Mass Transfer 51 1003-1016 :

[12]. Internet:http://www4.ncsu.edu/ doster/NE402/Text/TwoPhaseFlo w/TwoPhaseFlow.pdf, diakses pada Kamis, 11-10-2012. 


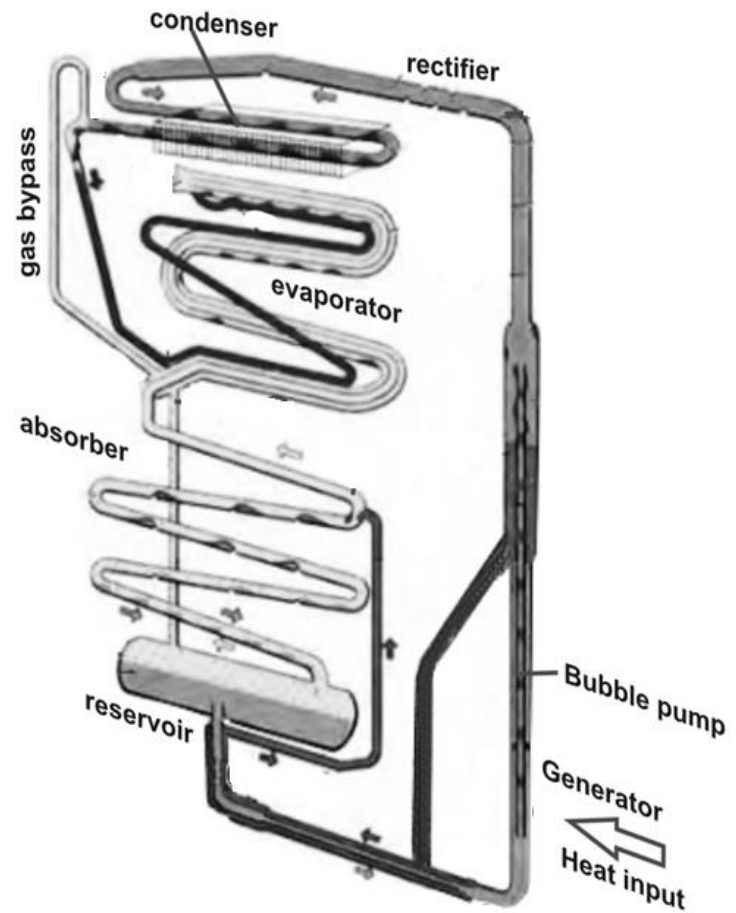

Figure 1. Diffusion Absorption Refrigerator R22-DMF Scheme

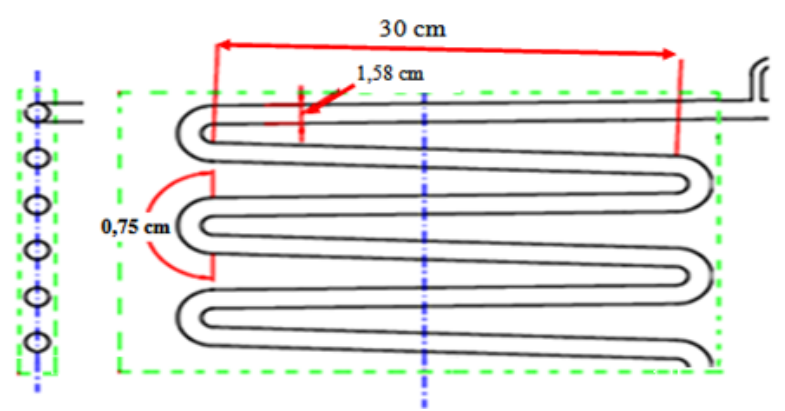

Figure 2. Evaporator Geometry and Domain

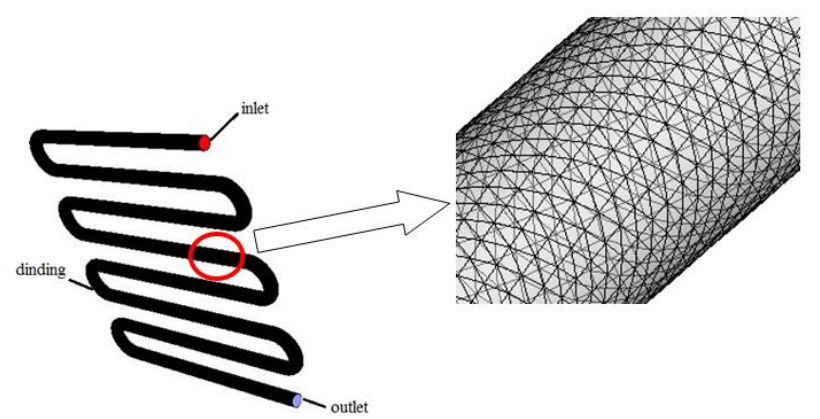

Figure 3. Schematic 3-dimensional testing and domain of numerical simulation

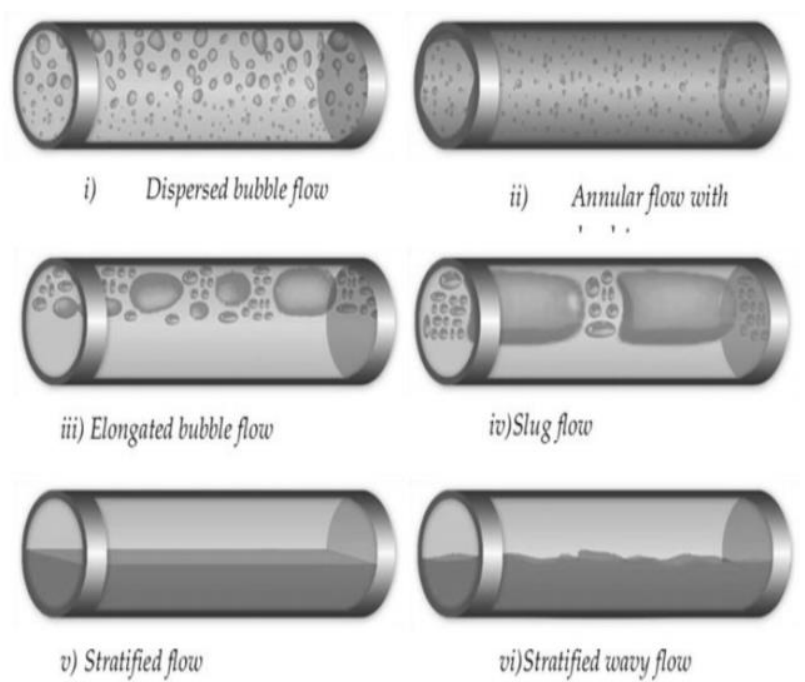

Figure 4. Gas-liquid flow regimes in horizontal pipes
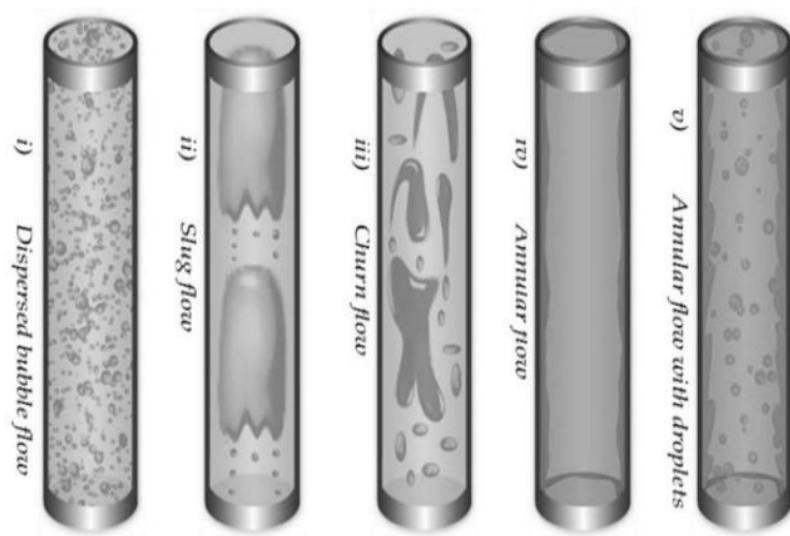

Figure 5. Gas-liquid flow regimes in vertical pipes
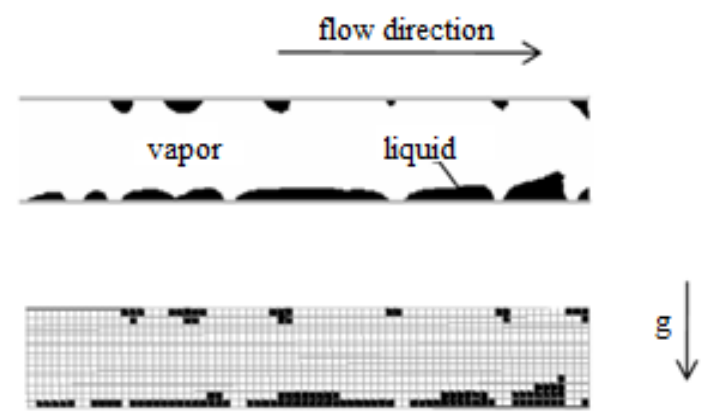

Figure 6. Wavy thin liquid film behavior 


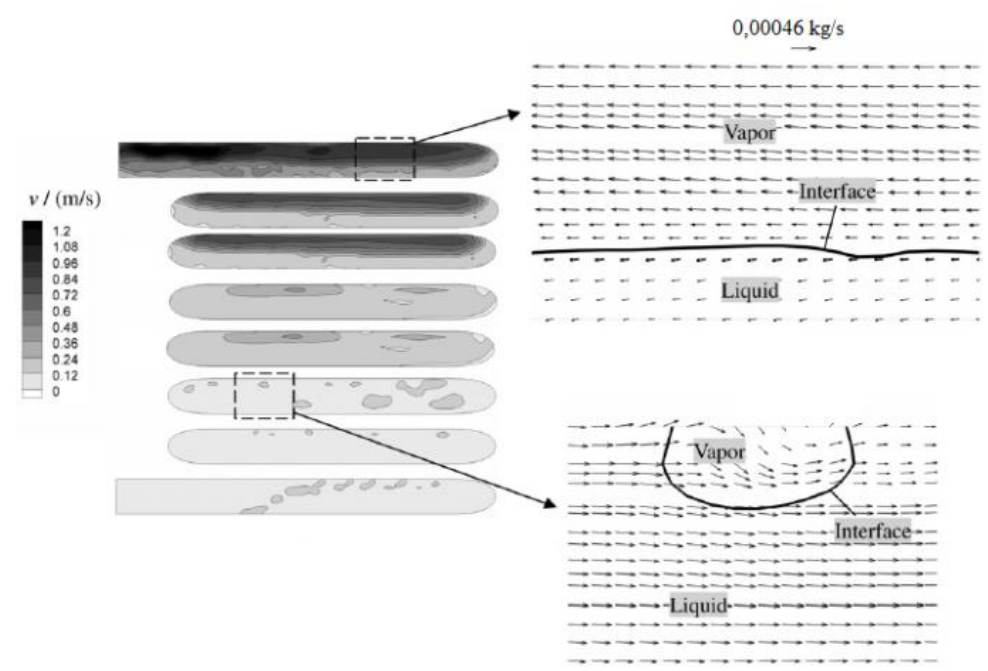

Figure 7. Velocity profiles

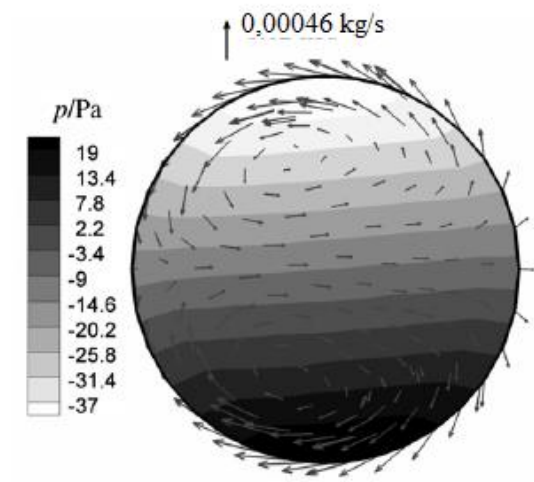

Figure 8. Secondary flow and pressure on bend cross-sections for single phase flow

TABLE 1.

CHLORODIFLUOROMETHANE (R22) CHARACTERISTIC

\begin{tabular}{|c|c|c|c|}
\hline \multicolumn{2}{|c|}{ Chlorodifluoromethane } & \multicolumn{2}{|r|}{ Properties } \\
\hline \multirow{6}{*}{ Fin' } & & Molecular formula & $\mathrm{CHClF}_{2}$ \\
\hline & & Molar mass & $86.47 \mathrm{~g} / \mathrm{mol}$ \\
\hline & & Appearance & Colorless gas \\
\hline & & Density & $3.66 \mathrm{~kg} / \mathrm{m}^{3}$ at $15^{\circ} \mathrm{C}$, gas \\
\hline & & Melting point & $-175.42^{\circ} \mathrm{C}, 98 \mathrm{~K},-284^{\circ} \mathrm{F}$ \\
\hline \multirow{2}{*}{\multicolumn{2}{|c|}{$\begin{array}{c}\text { IUPAC name } \\
\text { Chlorodifluoromethane }\end{array}$}} & Boiling point & $-40.7^{\circ} \mathrm{C}, 232 \mathrm{~K},-41^{\circ} \mathrm{F}$ \\
\hline & & Solubility in water & $\begin{array}{l}0.7799 \text { volvol at } 25^{\circ} \mathrm{C} ; \\
3.628 \mathrm{~g} / \mathrm{L}\end{array}$ \\
\hline \multirow{5}{*}{\multicolumn{2}{|c|}{$\begin{array}{c}\text { Other names [hide] } \\
\text { Difluoromonochloromethane, } \\
\text { Monochlorodifliuoromethane, HCFC-22, R-22, } \\
\text { Genetron 22, Freon 22, Arcton 4, Arcton 22, UN } \\
\text { 1018, }\end{array}$}} & $\log P$ & 1.08 \\
\hline & & Vapor pressure & $908 \mathrm{kPa}$ at $20^{\circ} \mathrm{C}$ \\
\hline & & $\mathrm{k}_{\mathrm{H}}$ & $0.033 \mathrm{~mol} . \mathrm{kg}^{-1} . \mathrm{bar}^{-1}$ \\
\hline & & & Structure \\
\hline & & Molecular shape & Tetrahedral \\
\hline & & Hazards \\
\hline \multicolumn{2}{|r|}{$\begin{array}{l}\text { Identitiers } \\
75-45-6^{\prime}\end{array}$} & R-phrases & R59 \\
\hline PubChem & & S-phrases & S23 S24 S25 S59 \\
\hline ChemSpider & & \multirow[t]{3}{*}{ Main hazards } & \multirow{3}{*}{$\begin{array}{l}\text { Dangerous for the } \\
\text { environment }(\mathbf{N}) \text {, Central } \\
\text { nervous system depressant, } \\
\text { Carc. Cat. } 3\end{array}$} \\
\hline EC number & & & \\
\hline KEGG & $200-0,1-2$ & & \\
\hline ChEMBL & & \multirow{3}{*}{ NFPA 704} & \\
\hline RTECS number & PA6390000 & & \\
\hline \multirow[t]{3}{*}{ Jmol-3D images } & Image 1 通 & & \\
\hline & SMILES & \multirow{2}{*}{$\begin{array}{l}\text { Autoignition } \\
\text { temperature }\end{array}$} & \multirow{2}{*}{$632^{\circ} \mathrm{C}$} \\
\hline & InChl & & \\
\hline
\end{tabular}


TABLE 2.

DIMETHYLFORMAMIDE (DMF) CHARACTERISTIC

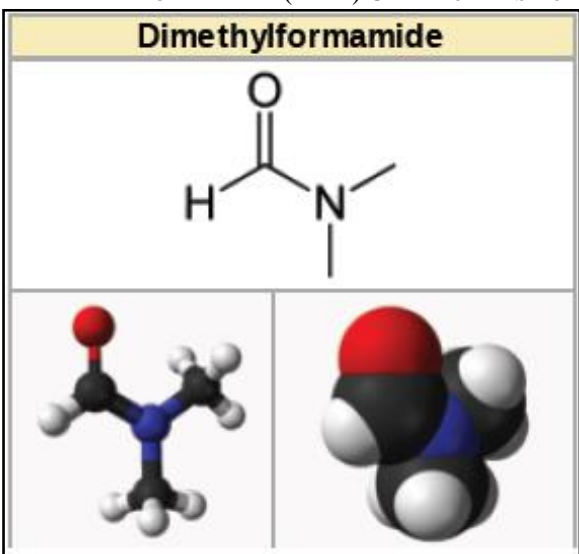

\begin{tabular}{|c|c|c|c|}
\hline \multirow{2}{*}{\multicolumn{2}{|c|}{$\begin{array}{c}\text { IUPAC name } \\
\mathrm{N}, \mathrm{N} \text {-Dimethylformamide }{ }^{[1]}\end{array}$}} & \multirow{2}{*}{\begin{tabular}{|l|} 
Density \\
Melting point
\end{tabular}} & \multirow{2}{*}{$\begin{array}{l}0.948 \mathrm{~g} \mathrm{~mL}^{-1} \\
-60^{\circ} \mathrm{C}, 212.7 \mathrm{~K},-77^{\circ} \mathrm{F}\end{array}$} \\
\hline & & & \\
\hline \multicolumn{2}{|c|}{ Other names } & & $152-1$ \\
\hline \multicolumn{2}{|c|}{$\mathrm{N}, \mathrm{N}$-Dimethylmethanamide ${ }^{\text {[citation needed] }}$} & & $305-309^{\circ} \mathrm{F}$ \\
\hline \multicolumn{2}{|c|}{ Identifiers } & Solubility in w ater & Mscible \\
\hline \multicolumn{2}{|r|}{$68-12-2$} & $\log P$ & -0.829 \\
\hline PubChem & 6228 & Vapor pressure & $516 \mathrm{~Pa}$ \\
\hline ChemSpider & $5993 \checkmark$ & $\lambda_{\max }$ & $270 \mathrm{~nm}$ \\
\hline UNII & $8696 \mathrm{NHOY} 2 \mathrm{X}^{\prime}$ & Absorbance & 1.00 \\
\hline EC number & $200-679-5$ & Refractive index $\left(n_{\mathrm{D}}\right)$ & $1.4305(a$ \\
\hline UN number & 2265 & Viscosity & $\left.20^{\circ} \mathrm{C}\right)$ \\
\hline DrugBank & DB01844 & \multicolumn{2}{|c|}{ Structure } \\
\hline KEGG & C03134 $\checkmark$ & Dipole moment & $3.86 \mathrm{D}$ \\
\hline $\mathrm{MeSH}$ & Dimethylformamide & \multicolumn{2}{|c|}{ Thermochemistry } \\
\hline $\mathrm{Ch} \boxplus \mathrm{Bl}$ & CHB⿴囗:17741 J & Std enthalpy of & $238.2 \mathrm{~kJ} \mathrm{~mol}^{-1}$ \\
\hline ChEMBL & CHEMBL268291 & Tormation $\Delta_{\mathrm{f}} \mathrm{H}_{208}$ & \\
\hline RTECS number & LQ2100000 & $\begin{array}{l}\text { Std enthalpy of } \\
\text { combustion } \Delta_{c} H^{\circ}\end{array}$ & $\begin{array}{l}-1.9428--1.9404 \mathrm{MJ} \\
\mathrm{mol}^{-1}\end{array}$ \\
\hline Beilstein Reference & 605365 & \multirow{2}{*}{$\begin{array}{l}\text { Specific heat capacity, } \\
\text { C }\end{array}$} & \multirow[t]{2}{*}{$146.05 \mathrm{~J} \mathrm{~K}^{-1} \mathrm{~mol}^{-1}$} \\
\hline 3DMet & B00545 & & \\
\hline \multirow[t]{2}{*}{ Jmol-3D images } & \multirow{2}{*}{ 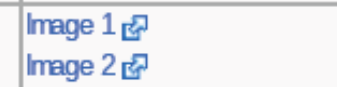 } & \multicolumn{2}{|c|}{ Hazards } \\
\hline & & GHS pictograms & \\
\hline \multicolumn{2}{|c|}{ SMILES } & & \\
\hline \multicolumn{2}{|r|}{ InChl [show] } & & \\
\hline \multicolumn{2}{|c|}{ Properties } & & \\
\hline Molecular formula & $\mathrm{C}_{3} \mathrm{H}_{7} \mathrm{NO}$ & & \\
\hline Molar mass & $73.09 \mathrm{~g} \mathrm{~mol}^{-1}$ & GHS signal word & DANGER \\
\hline Appearance & Colourless liquid & GHS hazard & H1226, \\
\hline Odor & fishy, ammoniacal & statements & $\underline{\mathrm{H}} 360$ \\
\hline
\end{tabular}

